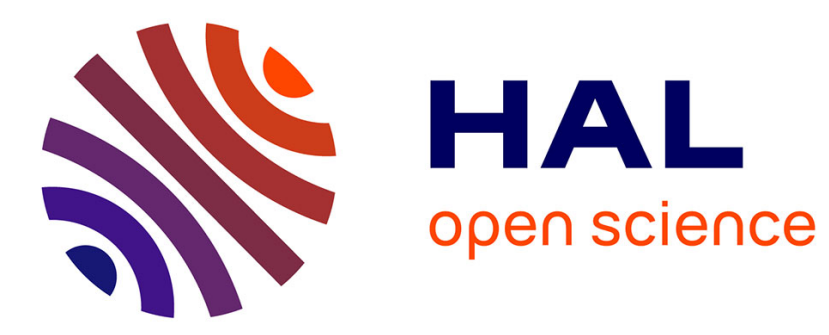

\title{
Dynamic material properties and terminal ballistic behaviour of shock-loaded silicon-nitride ceramics
}

\author{
H. Nahme, V. Hohler, A. Stilp
}

\section{To cite this version:}

H. Nahme, V. Hohler, A. Stilp. Dynamic material properties and terminal ballistic behaviour of shockloaded silicon-nitride ceramics. Journal de Physique IV Proceedings, 1994, 04 (C8), pp.C8-237-C8-242. 10.1051/jp4:1994835 . jpa-00253390

\section{HAL Id: jpa-00253390 https://hal.science/jpa-00253390}

Submitted on 1 Jan 1994

HAL is a multi-disciplinary open access archive for the deposit and dissemination of scientific research documents, whether they are published or not. The documents may come from teaching and research institutions in France or abroad, or from public or private research centers.
L'archive ouverte pluridisciplinaire HAL, est destinée au dépôt et à la diffusion de documents scientifiques de niveau recherche, publiés ou non, émanant des établissements d'enseignement et de recherche français ou étrangers, des laboratoires publics ou privés. 


\title{
Dynamic material properties and terminal ballistic behaviour of shock-loaded silicon-nitride ceramics
}

\author{
H. Nahme, V. Hohler and A. Stilp \\ Ernst-Mach-Institut, Eckerstrasse 4, 79104 Freiburg, Germany
}

\begin{abstract}
Résumé
Les effets dynamiques et la structure microscopique des matériaux céramiques de silice-nitride chargées par ondes de choc possédant deux densités différentes ont été examinés à l'aide de l'impact de plaque planar et de la technique VISAR. De plus, le comportement balistique terminal des deux céramiques a été déterminé. Les résultats combinés obténus par les expériences effectuées suggèrent une influence importante de la microstructure sur le comportement balistique terminal et par conséquent sur la capacité de protection des céramiques soumis à l'impact.
\end{abstract}

\begin{abstract}
The dynamic properties and microscopic material structure of shock loaded Silicon-Nitride ceramics of two different densities have been investigated by means of the planar plate impact and VISAR technique. In addition the terminal ballistic behaviour of both ceramics has been determined. The combined results of the tests performed suggest an important influence of the microstructure on the terminal ballistic behaviour and thus on the ceramics protection capability against impact processes.
\end{abstract}

\section{Introduction}

For many years a large variety of ceramics have been tested with respect to their protection capability against impact processes $/ 1 /$. Despite extensive studies, a general relation between the terminal ballistic behaviour and the static and dynamic material properties has still not been established. The studies of the dynamic and terminal ballistic behaviour and the microstructure of $\mathrm{Si}_{3} \mathrm{~N}_{4}$ ceramics having two different densities due to different amounts of porosity presented here are a contribution to this still unresolved problem.

\section{Experimental Setup}

The dynamic material properties have been determined using the planar plate impact technique $/ 2 /$ in connection with a VISAR (Velocity Interferometer System for Any Reflector) $/ 3 /$ and sample recovery techniques. The experimental setup is shown schematically in figure 1 . The projectile plates were C45 - steel with a thickness of 3-4 $\mathrm{mm}$ and a diameter of $58 \mathrm{~mm}$. The ceramic targets have been plates of $50 \mathrm{~mm}$ diameter and thicknesses of $5 \mathrm{~mm}<\mathrm{d}_{\mathrm{T}}<25 \mathrm{~mm}$. All plates have been prepared to be plane and parallel to better than $0.2 \mathrm{mrad}$. The tilt between projectile and target at the moment of impact was in the range of $1 \mathrm{mrad}$. The projectiles have been accelerated using a single stage compressed air gun and a powder gun. The bore diameter of the barrel was $70 \mathrm{~mm}$. Impact velocities in the range $200 \mathrm{~m} / \mathrm{s}<\mathrm{v}<1180 \mathrm{~m} / \mathrm{s}$ yielded maximum stresses applied to the samples in the range of $2 \mathrm{GPa}<\sigma_{\max }<16 \mathrm{GPa}$. By means of the VISAR the velocity history of the target rear surface has been recorded with a time resolution of $2 \mathrm{~ns}$. 


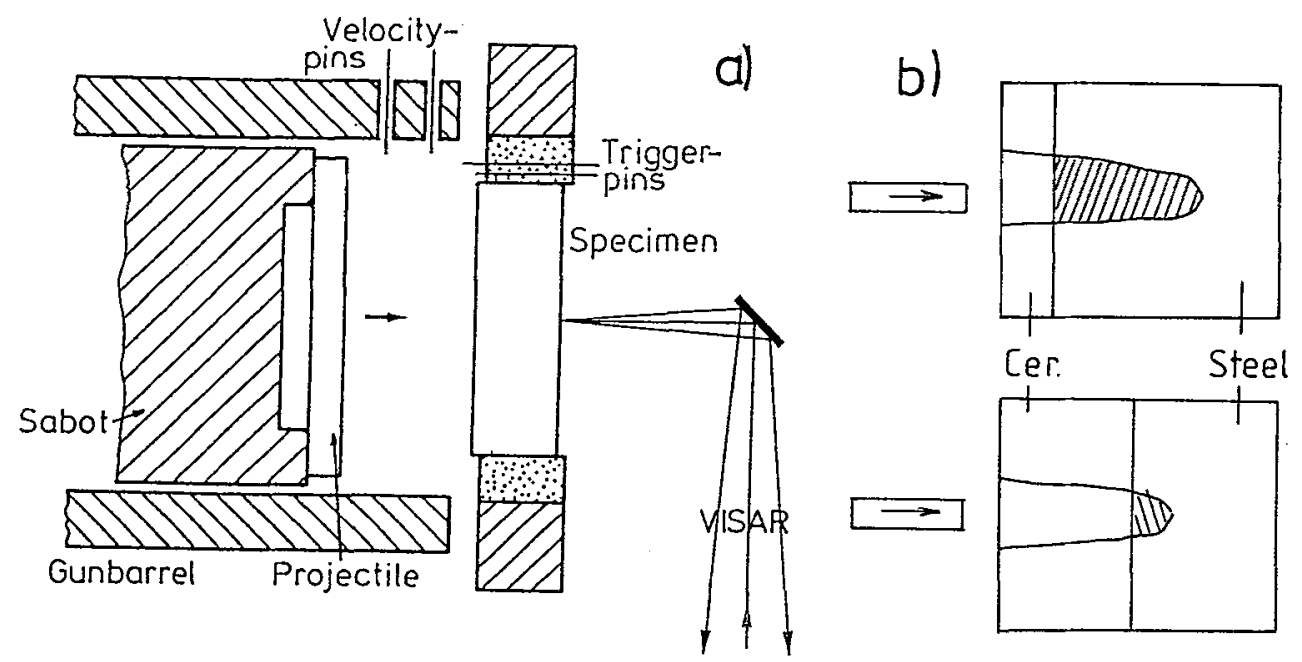

Figure 1: Experimental setup (schematically)

a) plate impact experiments

b) DOP-method

Experiments up to $400 \mathrm{~m} / \mathrm{s}$ impact velocity have been recovery experiments. Sample fragments have been examined by means of scanning electron microscopy.

A brief desciption of wave propagation in shock loaded target plates is given elsewhere in this volume $/ 4 /$.

The terminal ballistic protection capability of both ceramics have been studied by means of the DOP-method (Depth of Penetration, fig. 1b). With this technique the penetration of a kinetic energy projectile into a steel target is determined for different thicknesses of protecting ceramic layers being lacated in front of the steel target. A high strength German armor steel of hardness $440 \mathrm{HV}_{20}$ was used. Single ceramic tiles of $130 * 130 \mathrm{~mm}^{2}$ lateral dimension and $18 \mathrm{~mm}$ thickness were piled until the required areal density was reached. The gaps between the ceramic tiles have been filled with epoxy, the surfaces were as received from the manufacturer.

The projectiles were made of tungsten-sinter material of density $17.6 \mathrm{~g} / \mathrm{cm}^{3}$, tensile strength of 1.2 GPa and an elongation at fracture of $10 \%$. The projectile diameter was $5.8 \mathrm{~mm}$ and the length was $72.5 \mathrm{~mm}$. Impact velocity was around $1700 \mathrm{~m} / \mathrm{s}$ for all tests.

The densities of the $\mathrm{Si}_{3} \mathrm{~N}_{4}$ samples were $2.28 \mathrm{~g} / \mathrm{cm}^{3}$ and $3.15 \mathrm{~g} / \mathrm{cm}^{3}$ for the porous and the solid material respectively. They will be denoted as $2.28-\mathrm{Si}_{3} \mathrm{~N}_{4}$ and $3.15-\mathrm{Si}_{3} \mathrm{~N}_{4}$ in the following text. The longitudinal sound velocities are listed in table 1.

\section{Experimental Results and Discussion}

Velocity histories measured by the planar plate impact technique are given in figure 2 for both materials. The results for the $3.15-\mathrm{Si}_{3} \mathrm{~N}_{4}$ are very similar to those known for

other ceramics. A high elastic precursor yields a high Hugoniot elastic limit (HEL) and is followed by a further velocity increase due to a "plastic" wave when the stress applied exceeds the HEL significantly. For this material in some cases a clear spall signal has been found. The release wave from the projectile rear surface finally leading to the spall process is in quite good temporal conformity with the values expected from the sample dimensions and known wave velocities.

A completely different behaviour is to be seen for the $2.28-\mathrm{Si}_{3} \mathrm{~N}_{4}$. All curves exhibit a clear elastic precursor being significantly lower than that of the $3.15-\mathrm{Si}_{3} \mathrm{~N}_{4}$. A second velocity increase follows with a considerable delay. When the impact velocity is increased to more than $800 \mathrm{~m} / \mathrm{s}$ and the applied stress exceeds $5.2 \mathrm{GPa}$, a second sharp structure is observed, followed by a further velocity increase. The spall strength determined from the spall signals sometimes is approximately one half of the strength of the 3.15- $\mathrm{Si}_{3} \mathrm{~N}_{4}$ but in several cases no spall signal was observed. In these cases a small velocity reduction was observed, but the reacceleration process is missing. This indicates, that the shock loaded material is of sufficient internal strength for the release wave to be transmitted, but there is no spall strength left. 


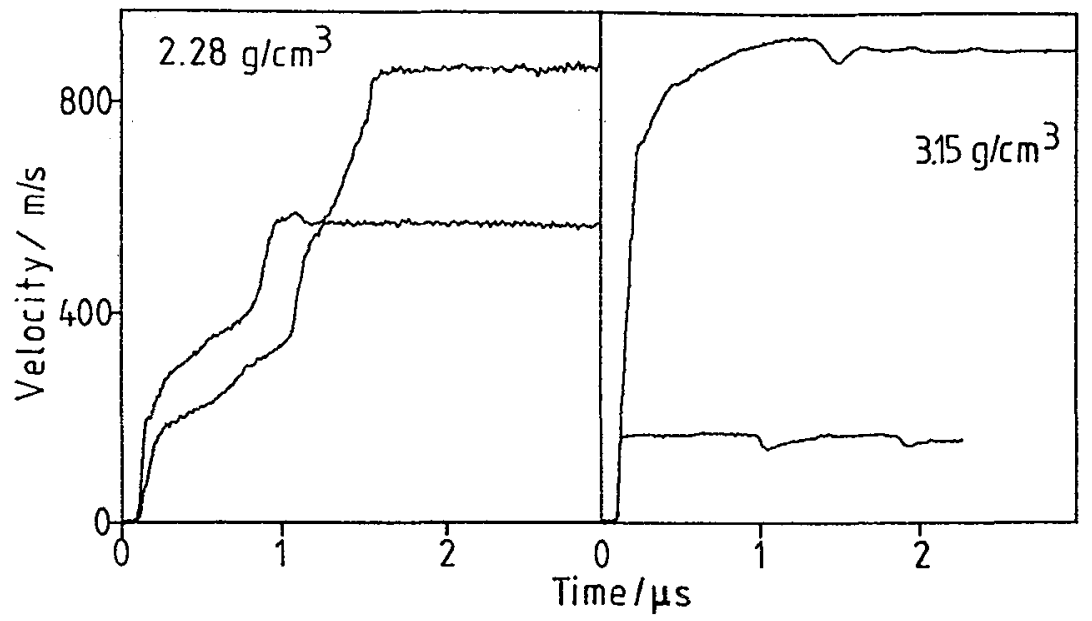

Figure 2: Velocity history curves of $\mathrm{Si}_{3} \mathrm{~N}_{4}$ ceramics

From the amplitude of the elastic precursor $\mathrm{u}_{\mathrm{HEL}}$ and the velocity decrease due to spallation $\Delta \mathrm{u}_{\mathrm{sp}}$ $\sigma_{\mathrm{HEL}}$ and the spall strength $\sigma_{\mathrm{sp}}$ of the materials have been evaluated using

$$
\begin{aligned}
& \sigma_{\mathrm{HEL}}=\rho \mathrm{c}_{1} \mathrm{u}_{\mathrm{HEL}} / 2 \\
& \sigma_{\mathrm{sp}}=\rho \mathrm{c}_{1} \Delta \mathrm{u}_{\mathrm{sp}} / 2
\end{aligned}
$$

respectively with the initial density $\rho$ and the longitudinal sound velocity $c_{1}$. The shock velocity $U_{\mathrm{s}}$, the maximum stress $\sigma_{\max }$ and maximum strain $\epsilon_{\max }$ have been calculated using

$$
\begin{aligned}
& \mathrm{U}_{\mathrm{s}}=\mathrm{c}_{\mathrm{l}} /\left(1+\left(\mathrm{c}_{\mathrm{l}} \Delta \mathrm{t} / \mathrm{d}_{\mathrm{T}}\right)\right) \\
& \sigma_{\max }=\sigma_{\mathrm{HEL}}+\rho \mathrm{U}_{\mathrm{s}}\left(\mathrm{u}_{\max }-\mathrm{u}_{\mathrm{HEL}}\right) / 2 \\
& \epsilon_{\max }=\left(\left(\mathrm{u}_{\mathrm{HEL}} / \mathrm{c}_{\mathrm{l}}\right)+\left(\left(\mathrm{u}_{\max }-\mathrm{u}_{\mathrm{HEL}}\right) / \mathrm{U}_{\mathrm{s}}\right)\right) / 2
\end{aligned}
$$

with the target thickness $d_{T}$ and the time interval $\Delta t$ between elastic and plastic wave. The HELs of 2.28- $\mathrm{Si}_{3} \mathrm{~N}_{4}$ depend on the target thickness and exhibit a precursor decay as it is known from some metals $15 /$.

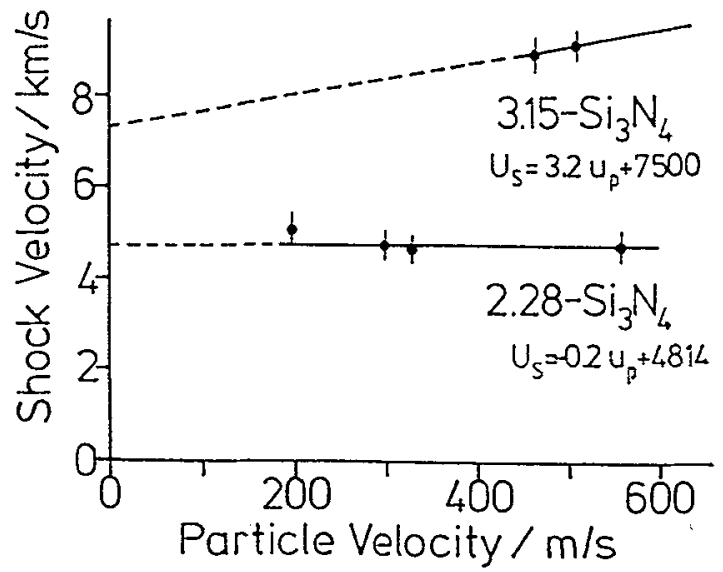

Figure 3: Shock velocity - particle velocity diagram for $\mathrm{Si}_{3} \mathrm{~N}_{4}$ ceramics 
In fig. 3 the $U_{s}-u_{p}$ data of both materials are displayed. Despite the fact that only for a few tests the HEL was exceeded for $3.15-\mathrm{Si}_{3} \mathrm{~N}_{4}$ a slightly increasing shock velocity is indicated. The nature of the delay of the second velocity increase for porous $2.28-\mathrm{Si}_{3} \mathrm{~N}_{4}$ is still questionable. There are four possible explanations for the observed velocity histories:

1. Reflection of the elastic precursor at the plastic wavefront propagating with lower velocity.

2. Reflection of the elastic precursor at a failure wave front.

3. Collapse of the voids and compression of the destroyed material.

4. Behaviour like $\mathrm{TiB}_{2}$

If reflection of the elastic precursor at the plastic wave front is responsible for the subsequent velocity steps the propagation velocity for the plastic wave front has been calculated from the time intervals between the velocity steps to be $2000 \mathrm{~m} / \mathrm{s}<\mathrm{u}<3400 \mathrm{~m} / \mathrm{s}$. The same calculation holds if the elastic precursor is not reflected at the plastic wave front but at a failure wave propagating into the material. Behind this wave front the material is totally fragmented. This leads to a region of reduced shock impedance reflecting the arriving release wave back to the rear target surface as a pressure wave. This mechanism would be very similar to that observed in glass by and Raiser and Clifton $/ 6 /$. A collapse of voids normally would lead to a more shallow velocity increase and is in view of the observed sharp structures in the velocity curves improbable. If processes are responsible like in $\mathrm{TiB}_{2}$ the nature of these processes is still being debated.

From the velocity histories the stress - strain relations given in fig. 4 have been evaluated. Because of the small number of tests only a linear fit has been applied. The fit parameters are also given in table 1 .

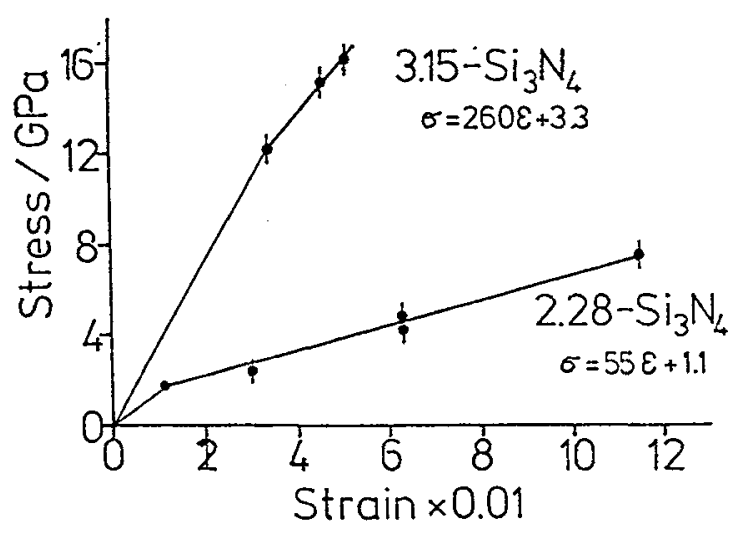

Figure 4: Stress - strain diagram for $\mathrm{Si}_{3} \mathrm{~N}_{4}$-ceramics

Table 1. Dynamic properties of $\mathrm{Si}_{3} \mathrm{~N}_{4}$ ceramic

$\rho=$ density $/ \mathrm{g} / \mathrm{cm}^{3}, c_{1}=$ long. sound speed $/ \mathrm{m} / \mathrm{s}, \sigma_{\mathrm{HEL}}=$ Hugoniot elastic limit $/ \mathrm{GPa}$ $\sigma_{\mathrm{sp}}=$ spall strength $/ \mathrm{GPa}, \mathrm{a}, \mathrm{b}=$ fitparameter of fig. 3 , c,d $=$ fitparameter of fig. 4

\begin{tabular}{l|l|l|l|l|l|l|l}
$\rho$ & $\mathrm{c}_{\mathrm{l}}$ & $\sigma_{\text {HEL }}$ & $\sigma_{\mathrm{sp}}$ & $\mathrm{a} / \mathrm{m} / \mathrm{s}$ & $\mathrm{b}$ & $\mathrm{c} / \mathrm{GPa}$ & $\mathrm{d} / \mathrm{GPa}$ \\
\hline 3.15 & 10660 & 12.1 & $0.5-0.8$ & 7500 & 3.2 & 3.3 & 260 \\
2.28 & 8600 & 1.9 & .25 & 4800 & 0.2 & 1.1 & 55
\end{tabular}

From the SEM-examination of the microstructure of both materials it can be seen that on a scale of a few microns both materials are of very similar structure. The density difference between both ceramics is due to voids in the range $10 \mu \mathrm{m}<\mathrm{d}<100 \mu \mathrm{m}$. On a scale below approximately $1 \mu \mathrm{m}$ the shape of the small particles are somewhat different with edged particles in the case of 3.15-Si ${ }_{3} \mathrm{~N}_{4}$ (fig. 5a) and smooth particle surfaces in the case of $2.28-\mathrm{Si}_{3} \mathrm{~N}_{4}$ (fig. 5b). In all sample fragments examined 
so far only a few coarse ceramic grains are contained. One of these grains is to be seen in fig.5c. Both types of samples contain regions of glassy resemblance (fig.5d) with an extension of up to several hundred $\mu \mathrm{m}$. The high number of these regions visible at the fragment surfaces indicate that either there is a high density of these regions spread throughout the material or this glassy material is more susceptible to tension stress than the crystalline ceramic material. Up to $400 \mathrm{~m} / \mathrm{s}$ impact velocity the material mainly breaks along its grain boundaries. Only few transcrystalline cracks in larger particles have been found (fig.5c).
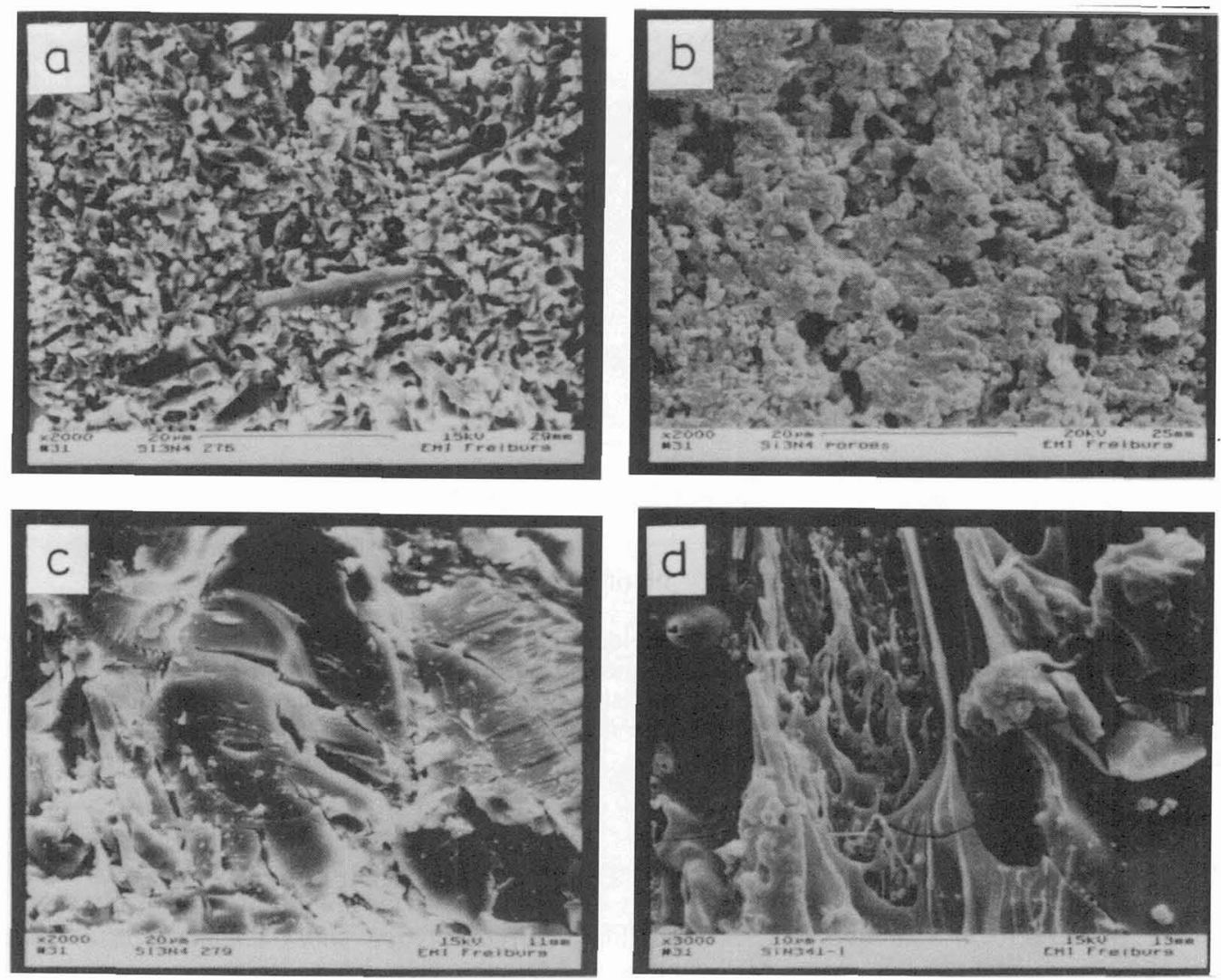

Figure 5: Microstructure of $\mathrm{Si}_{3} \mathrm{~N}_{4}$-ceramics (Description see text)

In fig. 6 the results of the DOP measurements are displayed. For comparison some results of other materials (German armor steel, $\mathrm{TiB}_{2}$ and $\mathrm{Al}_{2} \mathrm{O}_{3}$ ) are included. The penetration depth into the steel target protected by ceramic plates and normalized by the penetration depth without protection is given for varying areal densities of the protecting materials. According to these tests, $3.15-\mathrm{Si}_{3} \mathrm{~N}_{4}$ belongs to the best protective materials, comparable to $\mathrm{SiC}$ and only a little bit less effective than $\mathrm{TiB}_{2}$. Even the porous $2.28-\mathrm{Si}_{3} \mathrm{~N}_{4}$ is definitely more effective than $\mathrm{Al}_{2} \mathrm{O}_{3}$ of the same areal density. Especially at high areal densities the slighty steeper slope of the $\mathrm{Si}_{3} \mathrm{~N}_{4}$ data indicates an improved shielding capability.

One intention of these investigations is a better understanding of the shielding capability of ceramics by combining the results of the terminal ballistic tests and the dynamic material

properties. The results for both types of $\mathrm{Si}_{3} \mathrm{~N}_{4}$ show that neither one single dynamic material parameter nor a combination of different parameters can explain the difference in terminal ballistic behaviour of both materials. In addition the difference with respect to other materials can not be explained. However for many of the tested materials the required dynamic values are not known with sufficient accuracy. 


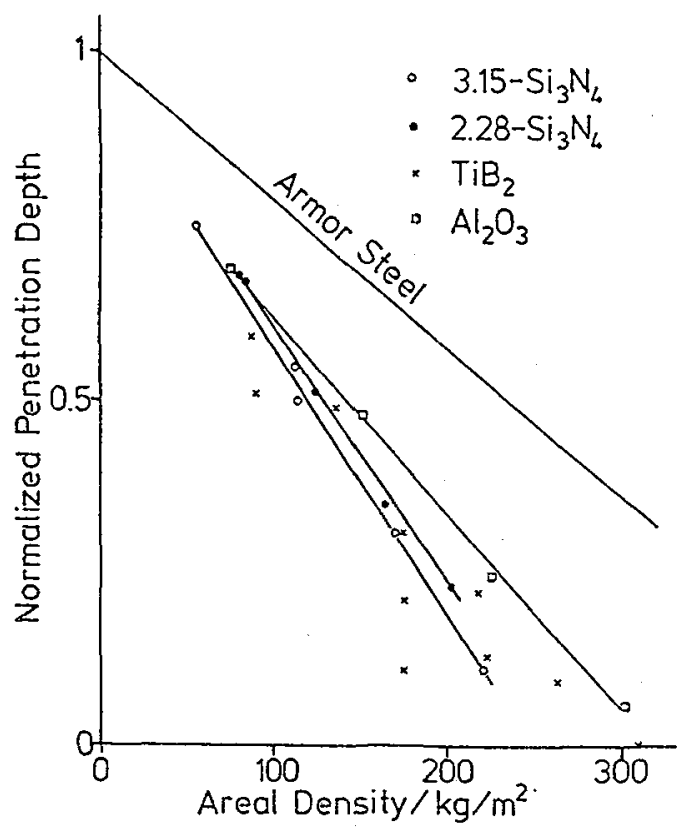

Figure 6: Depth of Penetration results

The SEM-examination of sample fragments yielded that in the microstructure beyond a few microns the structural differences between both materials nearly but not completely vanish. This result and the relatively small differences in the terminal ballistic behaviour despite the large differences in the dynamic properties may be an indication that the material's microstructure plays an important role in the terminal ballistic behaviour of ceramics.

\section{References}

11/ M.L.Wilkins, C.F.Cline, C.A.Honodel, "Fourth progress report of light armor program" UCRL-71817 (1969)

12/ L.M.Barker, M.Shahinpoor, L.C.Chhabildas, "High-pressure shock compression of solids" pp.43-73, Editors: J.R. Asay, M. Shahinpoor; Springer, New York, 1993

13/ L.M.Barker, R.E. Hollenbach, J. Appl. Phys. 43, pp.4669-4675, (1972)

/4/ H. Nahme, M.J. Worswick, this volume

/5/ W. Arnold, Ph.D. Thesis, Technical University Munich, 1991

/6/ G. Raiser, R.J.Clifton, Proc. of the APS-Meeting 1993, Colorado Springs, June 28th- July 2nd. 1993, in press 